http://ejtr.vumk.eu

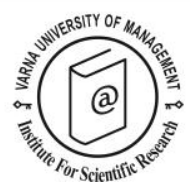

\title{
Why are small businesses engaged in sustainable tourism?
}

\author{
Samantha Isaac ${ }^{1}$
}

Received: 23/04/2018

${ }^{1}$ Leeds Beckett University, Macaulay Hall, Headingley Campus, Leeds, West Yorkshire, LS6 3QN, UK. Phone: +44 1138123492. E-mail: samisaacresearch@gmail.com

Supervisors: Dr Simon Woodward

Dr Davina Stanford

Institution awarding the Ph. D. Degree: Leeds Beckett University

Date of defence: $24 / 04 / 2017$

(C) 2018 Varna University of Management. All rights reserved

Citation: Isaac, S. (2018) Why are small businesses engaged in sustainable tourism? Doctoral Dissertation Summary. European Journal of Tourism Research 20, pp. 141-144

\section{Goal and objectives of the dissertation Goal}

Although small businesses have the potential to contribute towards the sustainability of a tourism destination, they do not always do so. The goal of this thesis is to understand small business engagement with sustainable tourism actions which take place both within their business and within the wider destination they operate in. It aims to identify what the reasons for engagement are and whether these vary between different types of action.

\section{Objectives}

In order to achieve this goal, the following objectives are addressed:

1. Identify the ways in which a small tourism business can contribute towards sustainability, both in terms of within their business and the wider destination they operate in.

2. From the literature, identify what is already known about small tourism businesses and why they may engage in sustainable tourism behaviour.

DOCTORAL DISSERTATION
3. Select a suitable case study area and identify four specific actions that small tourism businesses could carry out in that area to contribute towards its sustainability objectives.

4. In line with Ajzen's theory of planned behavior (1991), determine the levels of intention to carry out each of the actions, the significance of each of the three constructs of attitude toward the behaviour, subjective norm and perceived behavioural control and the underlying beliefs associated with these.

5. Draw conclusions about the reasons for acting sustainably across the four actions and what the implications are in terms of engaging small tourism businesses in sustainable tourism behaviour both within their business and within the wider destination they operate in.

\section{Methodology}

The research adopted an exploratory sequential mixed method approach within a case study area, the Northumberland Coast Area of Outstanding Natural Beauty 
Why are small businesses engaged in sustainable tourism? Doctoral Dissertation Summary.

(NCAONB). Interviews with 11 small business owners were carried out to elicit behavioural beliefs, normative beliefs and control beliefs for each of the different sustainable tourism actions being tested. The interviews were analysed using thematic analysis.

The findings from these interviews were then used to develop an online questionnaire. This consisted of five sections - one for each of the four actions being tested and a demographics section. This questionnaire was completed by a random sample of 190 tourism businesses within the case study area. Descriptive statistics were used to identify the levels of intention for carrying out each of the actions. Logistic regression was used to identify the most significant constructs.

\section{Results}

Four different types of sustainable tourism action were identified and tested. These types of action were: actions which take purely at a business level within the confines of the business $(A)$; actions which take place within the business but this time involve the visitor in some way (B); actions which also involve influencing visitor behaviour but within the destination itself rather than the confines of the business $(\mathrm{C})$ and actions where the point of impact is again within the destination itself (i.e. not within their own business), but do not require visitor action to achieve (D).

One specific action from each type was tested. These were: using low energy lighting within their business $(A)$, encouraging visitors to recycle onsite $(B)$, encouraging visitors to take part in car free activities (C) and supporting local producers by buying and using their products (D). These actions were identified by stakeholders in the case study area as being particularly pertinent to the NCAONB and actions that they would like businesses to be engaged with.

The research found that businesses were engaged with the four different actions investigated for different reasons. Attitude towards the behaviour was the most significant construct for the actions of using low energy lighting, encouraging recycling and supporting local producers, whilst in the case of encouraging car-free activities perceived behavioural control scored most strongly.

The underlying beliefs surrounding these actions varied. Whilst establishing differences between the actions, the study also found that some considerations were common across several different actions. These were namely that the impact on the visitor experience was perceived as important as well as there being some form of benefit present. The research also exposed the fact that actions have different points of impact and require different types and amounts of interaction with guests.

\section{Theoretical conclusions}

The study contributed to knowledge in several ways. It identified differentiated reasons for acting sustainably and presented a new way of categorising sustainable tourism actions by one of four action types (A, B, C and D). In contrast to previous studies it considered all aspects of sustainable tourism as possible actions for investigation and focused on comparing and contrasting reasons for implementation rather than identifying owner typologies. It highlighted the importance of addressing engagement with actions on an individual basis rather than taking a blanket approach to encouraging sustainability amongst small tourism businesses.

The research also showed the use of a forward incentive to participants to be an extremely effective way of getting respondents to complete an online survey. Before emailing the link to business owners, a small packet of biscuits and a teabag was sent in the post along with a covering letter explaining the research and that the questionnaire had been designed so that it could be completed in the time it took to have a cup of tea and a biscuit. This technique contributed to a response rate of $72 \%$ being achieved and proved a useful way of building rapport and engaging business owners with the study. The use of a forward incentive could be used in other studies to encourage participation. 


\section{Practical application of the dissertation}

The study has a practical application for destination management bodies who are trying to encourage businesses to act sustainably. As well as providing specific recommendations for the four actions of using low energy lighting, encouraging recycling, encouraging car-free activities and supporting local producers by buying and using their products it also identifies key considerations for successful implementation for any action, which should be borne in minding when working with small businesses. These include: to identify the action type and its complexity, to make it clear to business owners what their role is in terms of helping to achieve it and to explain why engagement with the action is important.

Whilst this study focussed on one case study area, the findings are applicable to other protected areas within the UK and indeed those further afield who wish to more successfully engage small tourism businesses in sustainable tourism activity.

\section{Content of the dissertation}

Abstract of Chapter 1

Chapter 1 begins by providing the context and rationale for the study. It then states the aim and objective and gives an outline of the structure of the thesis and the contents of the proceeding chapters. It also introduces the idea of different action types and in doing so, shows how this piece of research will approach the question of why small tourism businesses act sustainably in a different way to previous work.

\section{Abstract of Chapter 2}

Chapter 2 introduces the idea of sustainable tourism, discusses what constitutes a tourism destination and in particular a sustainable destination. After identifying the stakeholders present in a destination, it discusses destination management within the United Kingdom tourism context. The reasons for making the private sector, and in particular small tourism businesses, the focus of this research are also given, with a change in political context (which has placed a greater emphasis on the role of the private sector) and a move away from government to governance highlighted. A summary of how the private sector can contribute towards a destination's sustainability and why they should do so is also provided.

\section{Abstract of Chapter 3 \\ Chapter 3 explores the reasons why small businesses may engage with sustainable tourism behaviour. Possible motivations are presented as internal and external barriers and drivers. Internal factors comprise of: time, skills, cost, non-financial benefits to the business, difficulty understanding the term sustainable tourism, conceptualisation of responsibility, owner values and previous experiences. External factors include: suitable support, infrastructure, leadership, other business behaviour, local and national government regulations, a lack of visitor demand and negative visitor perceptions.}

\section{Abstract of Chapter 4}

Chapter 4 identifies an appropriate framework to guide the study. It begins with a critical review of different theoretical frameworks which could have been applied before identifying Ajzen's theory of planned behaviour as the most appropriate one to use. This specific framework and its application is then discussed.

\section{Abstract of Chapter 5}

Chapter 5 chapter provides an account of the mixed methods design, an exploratory sequential design utilising semi-structured interviews and a self-completion questionnaire. The identification of the case study area is also discussed, along with the data collection methods for both the qualitative and quantitative stages of the process and the data analysis techniques used. An analytical framework is also presented showing how the results from each stage of the research were integrated.

\section{Abstract of Chapter 6 \\ Chapter 6 describes how the case study area (NCAONB) was identified and provides the key characteristics of the protected area and its tourism features. It also outlines the process used to identify the key sustainable}


tourism actions within the destination and how the four actions of using lowing energy lighting $(A)$, encouraging visitors to recycle onsite $(B)$, encouraging visitors to take part in car free activities (C) and supporting local producers by buying and using their products (D) were chosen.

\section{Abstract of Chapter 7 \\ Chapter 7 contains the results from the first stage of the data collection. The main purpose of the interviews was to elicit key behavioural, normative and control beliefs for each of the four sustainable tourism actions being investigated. The chapter starts with an overview of the respondents before reporting the beliefs elicited for each action and explaining how these were then incorporated into the questionnaire.}

\section{Abstract of Chapter 8}

Chapter 8 contains the results from the second stage of the data collection. The purpose of the questionnaire was to identify levels of intention towards carrying out the four different actions, as well as identify levels of agreement with the direct measure constructs of attitude, subjective norm and perceived behavioural control. An overview of the intention and direct measure results for the sample as a whole is given before focusing on each action in turn. The outcomes of the logistic regression procedures performed are discussed, with the underlying beliefs of the most significant constructs explored.

\section{Abstract of Chapter 9}

Chapter 9 draws on the results of the previous two chapters, with the key findings of the research discussed. A comparison of the four actions shows that whilst attitude was the most significant construct for three out of the four, the underlying beliefs varied between them and that there was merit in looking at engagement with actions at an individual rather than more general level. Recommendations for implementation are made in the form of key considerations which need to be taken when trying to engage small businesses in sustainable tourism behaviour.

\begin{abstract}
Chapter 10
Chapter 10 begins by providing evidence of how the research aim and objectives were met. It then goes on to show how the research gaps identified in Chapter 2 were addressed. After this a summary of the main findings of the study is presented, followed by an outline of the contributions to knowledge made. Next, it details the limitations of the research and the implications of these before making suggestions for areas of future research. It concludes with a reflection on the lessons learnt during the process of carrying out the study.
\end{abstract}

\section{References:}

Ajzen, I. (1991) The theory of planned behaviour. Organisational Behaviour and Human Decision Processes, 50, 179-211. 